\title{
Research on Primary Chinese Classics Reading Strategies based on Students Basic Accomplishment
}

\author{
Nanshuo Sun ${ }^{a}$, Jun Yang \\ School of Education and Sports, Bohai University, Jinzhou, 121013, China \\ a584346199@qq.com, b444530141@qq.com
}

Keywords: basic accomplishment; primary Chinese; classics reading; strategies

\begin{abstract}
The basic accomplishment of primary school students guided by core accomplishment is the requirement of reflecting the value of Chinese curriculum in the new period. Chinese teachers explore to build various forms to implement classic reading curriculum in the teaching practice: drawing and copying, personalized reading; based on class, environment education; learning and reading exhibition step by step; combination of knowledge and writing, environmental education; activities show, flowers open; parent-child reading, extending parents to take students as the main body. Guide students to feel the profound of classical culture and comprehensively enhance students' good listening, reading, speaking, writing ability, so as to enhance students' national literacy.
\end{abstract}

\section{Introduction}

In 2014, the Ministry of Education issued "On the curriculum reform to deepen the fundamental task of implementing Rucker culture views" (hereinafter referred to as "opinion"), which put forward the concept of "core competence". "Opinion" takes the core literacy system of the research and development of students' development as the key field and main link of promoting curriculum reform. Once the document was published, "core accomplishment" has become a hot topic in the educational field. Therefore, under the background of core accomplishment, what kind of Chinese teaching can effectively improve the students' core quality of Chinese, which is a problem that every Chinese teacher should think about.

\section{Connotation and Contents of Classic Reading Course based on Students Basic Accomplishment}

"Classic" is the crystallization of great wisdom and good emotion of a nation, which is contained in a very light transmission, humanism, the value is last long and new, any cultural system has its eternal classics as its source. A person in the childhood contacts most wisdom and valuable classics in the period with the purest mind and the best memory, which can lay his life lofty wisdom and excellent personality and become the cultural foundation for his life to continue to digest, understand and benefit. Educators must pay attention to students' cognitive level and age characteristics, leading students to approach classics happily.

The first of the "new curriculum standard" on "the basic idea of the course" is "comprehensively improve students' Chinese accomplishment", It is required that "Chinese curriculum should cultivate students' thoughts and feelings of loving Chinese language, guide students to correctly understand and use the Chinese language, enrich the accumulation of language, cultivate language sense and develop thinking", "Chinese curriculum should also pay attention to improve students' moral accomplishment and aesthetic taste, so that they will gradually form a good personality and sound personality, and promote the harmonious development of morality, intelligence, body and beauty". The Chinese curriculum as the basic course in the field of humanities, its value curriculum reflects four aspects of language construction and application, thinking development and promotion, aesthetic appreciation and creation, cultural understanding and transmission to prepare for students' 
further study, which makes students develop the quality that lifelong learning and development need, so as to form students' language accomplishment core [1].

The most needed mastery skills of primary school language teaching are to recognize, read, write. Grade one or two of primary school is the key period to understand Chinese characters; students in grade three or four are the best period to develop reading interest; grade five or six is the critical period to lay a foundation for writing. Psychologists have pointed out that human memory develops rapidly in childhood and reaches its peak at the age of thirteen. Seizing the golden age of child memory to let them read the classic, elegant and depth things that cultivates body and mind, develop intelligence and enhance ability, which keeps them in mind and benefit forever [2].

\section{Practical Significance on Classics Reading}

Reciting positive and healthy classical poetry prose can improve the individual's literary accomplishment. The characteristics of ancient poetry are short, every phrase a gem, often the word is amazing and revealing the secret word. Tempered sentences contain rich content, a good poem itself is a beautiful picture, a wonderful narrative. The reader can launch the rich imagination, heart greedy octupole and fugue maninsanin in the reading process. Ancient poetry plays an irreplaceable role in improving students' personal literature quality.

Chanting positive and healthy classical poems can shape the sense of belonging and pride of the nation. From the significance of ancient Chinese literature reading, ancient Chinese literature classic contains thousands of years excellent poems and songs handed down from the past, concentrates Chinese rhythm and beauty of diction, the theme implies value pursuit and aesthetic ideal of Chinese national tradition, glitters the patriotic glory which takes the world as the responsibility, shows the noble feelings with strive constantly, unite and forge ahead. With that reading classic mandarin language, enable students to feel and understand the philosophy of life, edify sentiment, nurtured by excellent cultural traditions, which is the best way for students to study and cultivation. Reading these classics not only enrich students' language materials, and ensure the quality of materials, first-class language materials obtained from the excellent poetry will glow boundless vitality and vigor in students' speech activities.

\section{Adopt Various Forms of Classical Reading Course, Comprehensively Enhance Students' Chinese Culture Accomplishment}

In order to effectively solve these problems, we should take various forms to develop reading courses. Organically combining the classic reading with literacy of grade one or two, which increases the amount of literacy of students and cultivates students' ability of autonomous learning; organically combining the classic reading and reading teaching, which cultivates students' interest in reading and appreciation ability, and enhances students' Chinese accomplishment; organically integrating the classic reading and composition teaching, which lets students to accumulate the classic verse, expand students' writing mentality and enhance the writing background; making auxiliary researches on the classic reading content selection and the current primary school Chinese teaching material content to edify the students' sentiment, correct the students' behavior through the classic reading [3].

In recent years, planning primary school with "sunshine reading" as the basis, innovating and implementing reading ability improvement projects, enhancing students' good listening, reading, speaking and writing ability, which explores and builds that students as the main body, with independent developed ancient Chinese literature courses as a carrier, with "activity" as the link to guide students to feel, broad and profound classical culture, and enrich the inner spirit of students in the teaching practice. In the acquisition of knowledge, they naturally constraint their own behavior, the soul has been baptized and edify [4].

First, drawing and copying, individuality reading. In accordance with the low, middle and high school section, respectively the "four character reader" classic reading books are innovatively designed: painting books, copying books, reading books, creating books. Students make beautiful 
reading cards and store them in their own archives according to their own reading comprehension. Because of the limited amount of literacy, grade one or two children have reading difficulties, introducing stories with simple text by drawing methods, properly describing their understanding and taste of the story content, which forms a low grade "painting books". Grade three or four is the beginning stage of primary school students, they contact more and more words, but perceptual things cannot be understood. Teachers let them master a large number of words, sentences, which is the accumulation of reading knowledge, laying the foundation for the future writing, in order to build "copying books" for grade three or four. The children of grade five have the process of text interpretation, teachers mainly let students feel the emotion in the book, grasp the main tendency of the text, read out their own unique feelings. Considering the situation of children's learning, the school promotes "reading books" in the grade five. "Real reading" and "creative reading" are two ways of reading. "Real reading", that is real reading, which tries to read the original meaning of the text and understand the meaning of author express. This is a kind of "reappearance" reading. Let students of grade six read, comprehend, taste, edify, indulge and admire with the "creating books".

Second, based on class, environmental education. Creating "sunshine reading" classes with class as the unit, teachers and students of each class together design different styles of wall culture: "footsteps of growth", "small painting workshop", "read together, grow together" and "show my style". Each class is equipped with a bookcase, five hundred books for each classroom. Carry out book rafting activities. The number of books drifting in each class reaches more than two hundred, and the class reading time must be guaranteed two hours for every class in each week. The implementation of the "two listening and three reading" activities, the curriculum department and student department check the class morning reading and afternoon training situation every day, praising for good examples, and included in the class quantitative assessment. Schools carefully build culture walls, in accordance with students' cognition law, the classic sentences from the "three character classic", "disciple gauge", "weng to rhyme", "thousand characterclassic", "analects of confucius", "university", "moderate" are showed in the form of pictures and illustrations, which gives students a subtle and silent education [5].

Third, learning and reading exhibition step by step. Draw lessons from advanced schools' excellent practice, brainstorm, combine with the actual learning situation, create suitable for our school actual "learning, reading, understanding, exhibition" Chinese classical reading class teaching mode. Formulating the "primary school Chinese classics classroom implementation advice", combined with classic reading of each grade required from the nation, giving full play to the wisdom of each Chinese teacher. Every week, school leaders and Chinese group members listen to a classic recitation class, they discuss teaching methods of classical recitation together and repeatedly invite teaching staffs to our school to give guidance, the primary school ancient Chinese classic reading classroom teaching mode with "learning, reading, understanding, exhibition" is finally determined.

Learning is reviewing old knowledge. In view of the learning content that students learn in the last recitation class, each student is examined, so that students can show themselves.

Reading is the perception of first reading. Students learn new knowledge based on reviewing old knowledge, first, reading pronunciation and new words truly, as well as reading sentences fluently. This process is completed under the leading and inspection of the study group leader.

Understanding is understanding the text and knowing the gist. Students understand the verse and prose on the basis of reading sentences expertly. This process can be carried out in various forms for students, such as students can consult materials after class, and can also be completed through group cooperation. The purpose is to let students read up the ancient Chinese literature articles on the basis of understanding.

Exhibition, namely recitation, development, application and performance. The classic content each grade is different, so each grade has its own characteristics. The students recite the words on the basis of reading proficiently, skill comes by exercise, gradually will creatively study and apply.

Of course, this model is only formulated combined with the characteristics of students. 
Fourth, the combination of knowledge and writing, environmental education. Under the impetus of classical reading activities, the literacy level of students will be greatly improved. The school builds a platform for literacy for students, taking a class as a unit regularly to hold a literacy contest, two pairs of questions confrontation, frequently misspelled words, words should be known, synchronous writing period selected by "read king", posted in school dignitaries for commendation, which arouses the students' interest in literacy. The school set up a "land book pen community" to guide students to write "disciple rules" and other classic chapters. Organizing backbone teachers to set up the founder of school-based writing materials teams, inviting the city calligraphy association experts to guide the preparation of a set of primary school six grades founder writing school-based teaching materials. The teaching material is integrated with read, write, ancient Chinese literature classic accumulation, calligraphy instruction that lets teachers improve their accomplishment in the process of guiding students' practicing, which creates delicate gas in the atmosphere [6].

Fifth, activities show, flowers open. The cultivation of students' Chinese ability is essentially a kind of quality education, cultivating students' Chinese ability can lay a solid foundation for students' quality education, however, classical reading can improve pupils' psychological quality in their Chinese ability. Classics are not narrow, but focus on the classic of big culture, which guide each grade according to the characteristics of the grade to start activities. Make full use of traditional festivals to carry out "Sinology show", such as endless "Dragon Boat Festival", endless recitation of "Mid Autumn Festival". After students read the "village residence", "willow", "early spring", "spring day" and other poems about spring, teachers inspire them to look for spring and observe spring in nature, and expand the wings of imagination, write a creative composition on the basis of the content of poetry. Students' writing interest and writing level are greatly improved. The "disciple rules" activities of "chanting, painting, playing, speaking, writing, creating" carried out by grade two let students truly feel the charm of Chinese civilization. Daily morning classics, "three character classic exercises" and the recitation of disciple rules after school embody the strong classical atmosphere. Rich and colorful activities let students love Chinese culture, and consciously practice Chinese culture, but also guide parents to participate in, which greatly improves the effect of activity education.

Sixth, parents and children read together, extend parents. Schools use holidays, vigorously carry out "parent-child reading" activities, with the "scholarly family" selection, setting off the family reading boom. Promoting parents to participate in school teaching activities to create a strong classical atmosphere for students, which stimulates students' interest in reading and reciting classics, cultivating students' good habit of reading endorsement. This activity has got parents' understanding and support. Carrying out the "classic reading parent-child moment" activities makes the classic reading extended to the family, which enhances the students' Chinese accomplishment [7].

\section{Conclusion}

Sinology reading is not only beneficial to optimize the personality of students, revive the humanistic spirit, but also help to improve the students' Chinese accomplishment. Of course, in the process of Sinology reading, there are some confusions: How to let the Chinese classics reading course effective and sustainable development? How to build a better Chinese classic reading stage to let students really like? How to make Chinese classics reading root in rural primary school? How to make Chinese classics reading deeply? Such problems are expected to be solved in the study of Chinese classics. In a word, the Chinese core quality oriented teaching is the only way which must be passed to embody the Chinese curriculum value, teachers should change their teaching ideas, focus on students' core competence promotion, create Chinese situation and practice which are beneficial for students' core accomplishment development, and make themselves an example to cultivate students' Chinese core literacy.

\section{Acknowledgement}

This work is supported by Innovative training program for college students in 2017: Exploration 
and practice of "Chinese classics reading" into universities; Teaching reform project of Bohai university in 2015 (BDJG-15-YB-B-012); Postgraduate teaching reform project of Bohai university in 2016: Action research on "ability to advanced" under the primary school education professional master talent training mode reform; Research subject on teaching reform and on educational quality evaluation in Liaoning education evaluation association: Exploration and practice of "Chinese classics reading" into universities; "Professional degree graduate student case library" project of Bohai university in 2017: Primary school Chinese teaching design case library; Project of economic and social development in Liaoning in 2018: Research on the cultivation of core quality of normal education in the context of structural reform of supply side.

\section{References}

[1] L. C. Wu, "The study of classical reading in primary school Chinese teaching," Master's Degree of Sichuan Normal University, 2014.

[2] X. F. Zhu, "The study of classical reading in primary school Chinese teaching," Extracurricular Chinese, vol. 14, no. 8, pp. 134-134, 2015.

[3] J. Y. Zhang, "The effective implementation of classical reading in primary school Chinese Teaching," Asia-Pacific Education, vol. 3, no. 11, pp. 176-176, 2016.

[4] R. R. Ye, "Investigation and study of current situation on 'Chinese classics reading' of primary school: Take S primary school in Shanghai as an example," Master's Degree of Shanghai Normal University, 2012.

[5] T. T. Zhang, "Study on the current situation and countermeasures of classical reading of primary school students," Journal of Qiqihar Junior Teachers' College, vol. 32, no. 6, pp. 120-121, 2012.

[6] S. M. Ren, "Implicit educational wisdom in 'Teach is to not teach'," China Education Daily, 2014-2-17.

[7] S. Q. Zhou, "Exploration on classical reading multiple evaluation," Forum on Education Research, vol. 8, no. 10, pp. 1-1, 2009. 